\title{
Dissociation of Molecular Aggregates under High Hydrostatic Pressure: The Influence of Water Structure on Benzene Cluster Solubility
}

\author{
Arlan S. Gonçalves, ${ }^{a}$ Ernesto R. Caffarena ${ }^{b}$ and Pedro G. Pascutti*,b \\ ${ }^{a}$ Instituto de Biofísica Carlos Chagas Filho, Laboratório de Modelagem e Dinâmica Molecular, Bloco D, Sala 030, \\ Universidade Federal do Rio de Janeiro, Ilha do Fundão, 21941-902 Rio de Janeiro-RJ, Brazil
}

${ }^{b}$ Programa de Computação Científica, Fundação Oswaldo Cruz, Rio de Janeiro-RJ, Brazil

\begin{abstract}
Em condições críticas, a água pode solvatar moléculas hidrofóbicas, tornando-se um solvente poderoso para agentes apolares. Para discutir o efeito da pressão em agregados de benzeno em água, foram executadas seis simulações consecutivas de 5000 ps (picossegundos) por modelagem e dinâmica molecular de moléculas de benzeno inseridas em caixas d'água cúbicas em diferentes condições de pressão, de 1 bar a 5 kbar. O raio de giro, o coeficiente de difusão, a função de distribuição radial, o número de ligações hidrogênio entre as moléculas de água e a área acessível ao solvente, foram monitorados. Os resultados mostraram que acima de $3 \mathrm{kbar}$, a estrutura da segunda camada de solvatação desaparece e os agregados de benzeno desmembram-se gradualmente. Até 2 kbar, a solubilidade e a difusão das moléculas de benzeno são inversamente proporcionais ao aumento da pressão e acima de 3 kbar o comportamento é o inverso.
\end{abstract}

In some critical conditions water can solvate hydrophobic molecules, becoming a powerful solvent for nonpolar agents. To discuss the pressure effect on hydrated benzene clusters we carried out six consecutive $5000 \mathrm{ps}$ (pico seconds) molecular dynamics simulations of benzene molecules in water cubic boxes at different pressure conditions, ranging from 1 bar to 5 kbar. Radius of gyration, diffusion coefficient, radial atomic pair distribution functions, number of hydrogen bonds between water molecules and the solvent accessible surface were monitored. Results showed that above $3 \mathrm{kbar}$ the second hydration layer structure vanishes and the benzene clusters start to break up gradually. Up to $2 \mathrm{kbar}$, the solubility and diffusion of benzene molecules are inversely proportional to the increase of the pressure and above $3 \mathrm{kbar}$ this behavior is inverted.

Keywords: benzene, molecular dynamics, hydrophobic effect, pressure effect

\section{Introduction}

The solvation effect of non-polar substances, as well as the importance of water for stabilization of biomolecular systems such as proteins, DNA, and membranes has been extensively studied. ${ }^{1,2}$ The restructuring of liquid water during the process of transferring non-polar molecules into aqueous phase produces interesting phenomena such as the decrease of partial molar entropy, partial molar volume, and enthalpy of solute, along with the increase of heat capacity in normal conditions of temperature and pressure. ${ }^{3}$ The stability of biological macromolecules is mainly due to the control that ordered water exerts around hydrophobic molecules. ${ }^{4}$

In general, under normal conditions of temperature and pressure, the solubility of hydrophobic compounds in

\footnotetext{
*e-mail: pascutti@biof.ufrj.br
}

water is low, favoring their segregation and organization. Accordingly, the number of water molecules packed around hydrocarbon molecules can be an important measure of the partition coefficient for this solute in solution. ${ }^{5}$ However, it is possible to solvate hydrophobic compounds in aqueous solutions by changing physical conditions, since it has been shown that solubility of benzene molecules in water-benzene mixtures is enhanced by increasing of temperature and pressure in two different supercritical regions, the first one at $573 \mathrm{~K}$ and 324 bar and the second at $673 \mathrm{~K}{ }^{6}$

The change in the solvation capacity of water at higher pressures might be explained by the distortion of the hydrogen bond network structure, along with the reduction of its dielectric constant. ${ }^{6}$

In view of these properties, industrial processes at such high pressure and temperature conditions are of particular interest. Examples of them are: supercritical 
water oxidation (SCWO) and supercritical extraction, among others. ${ }^{7}$ For instance, SCWO becomes an important application because it provides a reliable way to destroy biochemical and pharmacological hazardous waste from industrial process, for example, the degradation of steam currents with aromatic compounds. ${ }^{6}$

The effect of pressure on the hydration of non-polar molecules is an interesting matter not only because of the so-called 'abnormal' behavior but also because its strong influence on different biological systems, like proteins, ${ }^{8}$ and organic solutions. In particular, its effect on the water self-diffusion coefficient and the solubility of hydrophobic solute is remarkable. ${ }^{9}$

Experimental techniques such as fluorescence spectroscopy ${ }_{10}^{10}$ Raman spectroscopic studies of compressed liquid water, ${ }^{11,12}$ neutron diffraction ${ }^{13}$ and X-ray diffraction ${ }^{14}$ indicated modifications in the structure of water surrounding hydrophobic compounds. Furthermore, the steady-state fluorescence anisotropy methodology has been widely employed by Gregorio Weber's laboratory to study the dissociation of protein subunits by dilution or by application of high hydrostatic pressure. ${ }^{15}$ Additionally, extensive experimental studies on the effect of pressure and temperature on the solubility of benzene and alkyl benzenes in water have been carried out by Sawamura et al. . $^{16-18}$

Among the techniques employed to understand water behavior at higher pressures, computer simulation methods, such as Monte Carlo (MC) and molecular dynamics (MD), have become powerful tools. They have extensively contributed to the analysis of the microscopic structure of the hydration shells, from a dynamical point of view, presenting the additional advantage of focusing the interest on some particular effects of an isolated system. Several reports ${ }^{19,20}$ have shown that water molecules, when surrounding a hydrophobic solute, are able to order themselves, invoking an analogy to the clathrate hydrate. Previous studies of hydration of non-polar compounds have utilized quasi-hydrophobic solutes combined with a polar or ionic compound acting as a solubility anchor. ${ }^{21}$ The disadvantage of this approach is that hydrophobic effects may be mixed up with hydrophilic ones, hindering the investigation. In this work we carried out MD simulations of eighteen benzene molecules immersed in a water box aiming to show the external pressure effect on the solubility and hydrophobicity of benzene.

\section{Methodology}

Atomic coordinates of benzene molecules were obtained from the GHEMICAL ${ }^{22}$ software and minimized with TRIPOS5.2 force field ${ }^{23}$ and their atomic partial charges were computed using ab initio calculation (Hartree-Fock method) with the GAMESS US ${ }^{24}$ program, $6-31 \mathrm{G}^{* *}$ basis sets along with the CHELPG ${ }^{25}$ approach. The benzene molecule was modeled using parameters of the OPLS-AA force field ${ }^{26,27}$ included in GROMACS (version 3.2.1) package. ${ }^{28,29}$

Eighteen benzene molecules were initially immersed in a cubic box $\left(52.23 \mathrm{~nm}^{3}\right)$ containing $1648 \mathrm{SPC}^{30}$ water molecules with periodic boundary conditions and this was the starting configuration. The system was then energy minimized using 1923 Steepest Descent steps along with 538 Conjugate Gradient steps. Particle Mesh Ewald ${ }^{31,32}$ (PME, Fourier spacing $1.2 \AA$, 4 th order and tolerance $10^{-5}$ ) and 6-12 Lennard-Jones potentials were applied to account for Coulomb and van der Waals interactions, using a cut-off of $0.9 \mathrm{~nm}$ for both interactions. The LINCS algorithm ${ }^{33}$ was applied over all covalent bonds intending to preserve the covalent character linkage between atoms.

Once the system was equilibrated after 500 ps of MD simulation, i.e. temperature reached $280 \mathrm{~K}$ and pressure 1 bar; six consecutive long runs (5000 ps) were carried out at different pressures, starting from 1 bar and gradually increased (1 kbar step) to $5 \mathrm{kbar}$. Trajectories were saved every $10 \mathrm{ps,}$ resulting in 500 snapshots for statistic analysis. The time step was chosen to be 0.002 ps for all simulations.

To analyze possible modifications of water structure with pressure in presence of hydrophobic solute, structural and dynamical functions such as solute radius of gyration, solvent accessible surface (SAS), self-diffusion coefficient and correlation functions of pairs such as: solute-solute, solute-solvent and solvent-solvent were computed. To better understanding the orientation properties of water hydration layers, the radial and angular distribution functions $g(r, \theta)$ were investigated.

The geometric parameters for $g(r, \theta)$ function are shown in Figure 1, where $r$ is the distance between oxygen atoms and the $\theta$ angle is defined by the vector normal to the plane containing the water molecule and the vector connecting the oxygen atom of this water molecule with another oxygen atom. Additionally, the angle between three neighboring oxygen atoms belonging to the second hydration shell was computed aiming to evaluate the pressure effect on the directional characteristics of the hydrogen bond network.

For each analysis we considered only the data corresponding to the last $3000 \mathrm{ps}$ of simulations for each pressure condition.

\section{Results and Discussion}

The formation of benzene clusters in aqueous solution at different values of hydrostatic pressures was analyzed through MD simulations. According to them, this system 


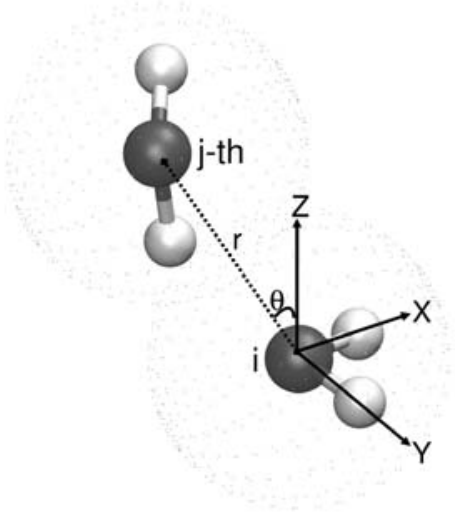

Figure 1. Geometric parameters for $g(r, \theta)$ function, where $\theta$ is the angle between the vector normal to the plane containing the water molecule centered on the oxygen atom (i) and the vector connecting the oxygen atom (i) and the oxygen atom of the $\mathrm{j}$-th molecule.

presented two different behaviors as a result of increasing hydrostatic pressure. At pressures below 2 kbar was observed the formation of benzene clusters with some isolated solvated benzene molecules. At $2 \mathrm{kbar}$, the aggregation of benzene reached its maximum while above $3 \mathrm{kbar}$ the benzene clusters progressively diminishes until $5 \mathrm{kbar}$, when they were no longer detected (Figure 2).

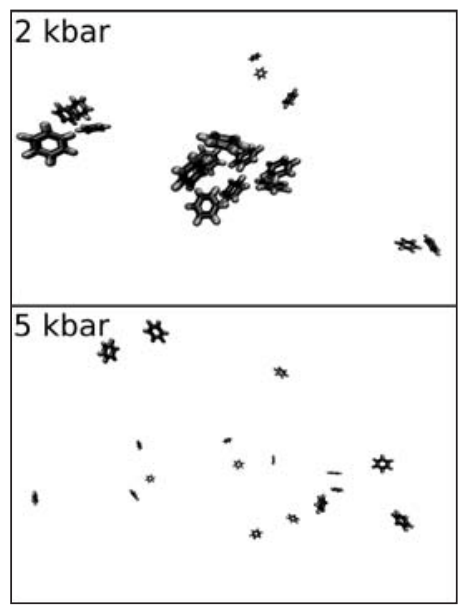

Figure 2. Last frame of molecular dynamics simulations at 2 and $5 \mathrm{kbar}$, respectively.

One way to quantify the effects of the pressure on the hydration of benzene is by calculating the distribution of mass of the eighteen benzene molecules as a whole using the radius of gyration, according to equation (1), where $m_{i}$ is the mass of atom $i$ and $x_{i}$ the position of atom $i$ with respect to the center of mass of the group of molecules and $\|x i\|$ is the norm of xi.

$R_{g}=\left(\frac{\sum_{i}\left\|x_{i}\right\|^{2} m_{i}}{\sum_{i} m_{i}}\right)^{\frac{1}{2}}$
Figure 3 shows that the radius of gyration of benzene arrangement presented lower values at $2 \mathrm{kbar}$ than at other evaluated pressures. From equation (1), the increase of benzene-benzene separation results in larger values of the gyration radius, and thus it can be used as a measure of benzene aggregation.

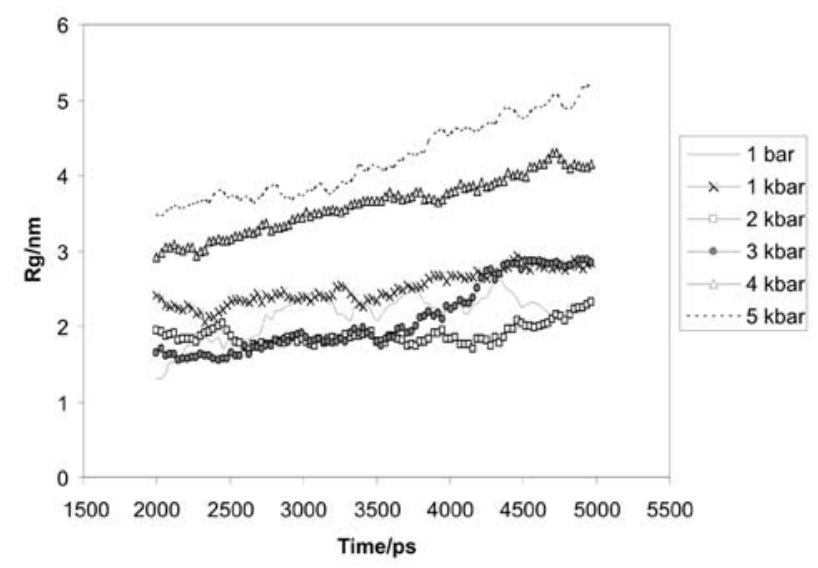

Figure 3. Radius of gyration for benzene molecules, computed at the time interval between 2000 and 5000 ps.

\section{Self-diffusion coefficient}

To further analyze the change in aggregation as a result of increasing pressure, the Einstein diffusion coefficient ${ }^{34}$ was computed according to equation 2 , taking into account only the last $3000 \mathrm{ps}$ for calculations, where $N$ is the number of particles and $x_{j}(t)$ stands for the position of the $j$-th particle at time $t$.

$$
D=\lim _{t \rightarrow \infty} \frac{1}{6 t}\left\langle\sum_{j}^{N}\left[x_{j}(0)-x_{j}(t)\right]^{2}\right\rangle
$$

The self-diffusion coefficient of benzene molecules in aqueous solution decreases as the pressure increases up to $2 \mathrm{kbar}$, then it increases with the pressure reaching values of that at 1 bar. This minimum coefficient is in agreement with the larger clustering of benzene at 2 kbar. In addition, we observed that water self-diffusion coefficients decrease almost linearly with the increase of the pressure (Figure 4). This result is supported by experimental data, given that dielectric constant and NMR measurements showed similar dependence for water diffusivity with pressure. ${ }^{35}$

\section{SAS}

The analysis of the hydrophobic SAS showed a clear drift towards higher exposure values resulted of an 


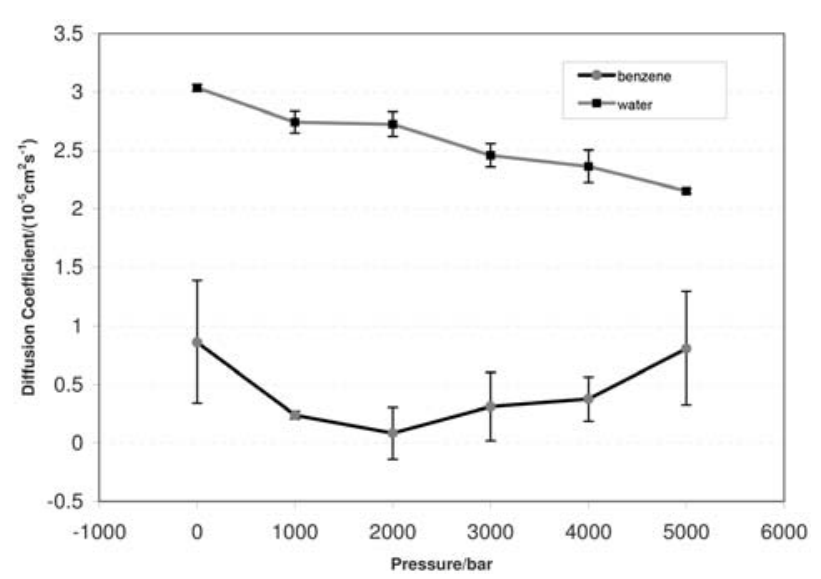

Figure 4. Dependence of diffusion coefficients with the pressure. The error bars correspond to the standard deviations for each simulation.

increment of the solubility of benzene in water, which may also be related to a change of the hydrophobic pattern. A plausible explanation for this observation might be achieved by assuming that pressure acts basically modifying the solvent structure through reducing the solvent capacity to effectively stabilize the molecular structure through the solvophobic effect. Figure 5 shows that a minimum of SAS is achieved at a pressure of $2 \mathrm{kbar}$, which coincides with the largest benzene clustering.

Clustering of benzene molecules was also observed at $2 \mathrm{kbar}$ during a hysteresis cycle. Hence, it is plausible that this pressure condition would favor the aggregation of hydrophobic compounds. ${ }^{36}$

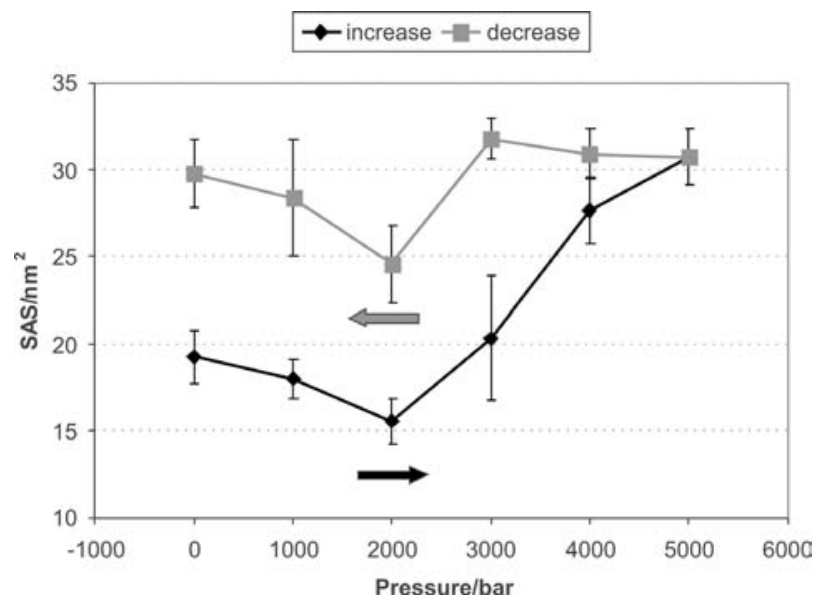

Figure 5. Average of solvent accessible surface in function of hydrostatic pressure, where the average in each point was computed between 2000 and 5000 ps of simulations and the error bar correspond to standard deviation.

\section{Structural features}

The change of benzene solubility in aqueous solution may be probably associated with the re-arrangement and distortion of the hydrogen bond (Hbond) network in the vicinity of the solute. Raman spectroscopic study ${ }^{12}$ of compressed liquid water have indicated that there is little, if any, Hbond breakage in response to the increased of hydrostatic pressure.

The maximum number of bonds that a water molecule can form is 4 at all the applied hydrostatic pressures. This number of interactions means that water in the vicinity of benzene molecules preserve its tetrahedral feature. It is noticeable that the total number of bonds was smaller at pressures between 2 and $3 \mathrm{kbar}$, returning to its normal value at higher pressures ( 4 and $5 \mathrm{kbar}$ ). This might be due to a lesser capability of solute access to solvent molecules. All histograms in Figure 6 were normalized according to the overall number of bonds found in the volume encompassing the solute and considering only the water molecules from up to $0.5 \mathrm{~nm}$ of any carbon atom of benzene molecules.

As pressure increases, water molecules in the vicinity of each solute re-accommodate themselves at closer distances bringing on a marked decrease of the intensities of the peaks (Figure 7). A combination of two factors might explain this behavior: the first one is that the number of atoms in the vicinity of benzene becomes larger due to the more packed structure resulting from the hydrostatic compression and bending of the hydrogen bond network; the second one might be due to the solubility change of benzene in aqueous solution.

However, it seems that the typical distance for hydrogen bonding remains unchanged as pressure increases. This fact shows that the connection between atoms involved in this type of interactions do not change considerably, but produces a reorganization of water molecules in the vicinity of solute, distorting rather than disrupting the hydrogen bond network.

The analysis of the angular distribution between water molecules involved in hydrogen bonds reinforces this statement. At lower pressures, the average angle for donors and acceptors for a single water molecule could be observed approximately at $120^{\circ}$ (Figure 8). At higher pressures, a symmetry breaking was seen resulting in a more heterogeneous angular distribution. The maximum at $120^{\circ}$ at lower pressures was split up into two peaks, differentiating the angle $110^{\circ}$ (for donors) and $130^{\circ}$ (for acceptors). It is important to note that the intensities of the peaks at higher pressures were higher, probably due to the larger amount of water molecules in the vicinity of the benzene molecules.

The effect of pressure on the association of benzene molecules and molecular packing of water in the vicinity of solute can also be directly obtained from the analysis of 

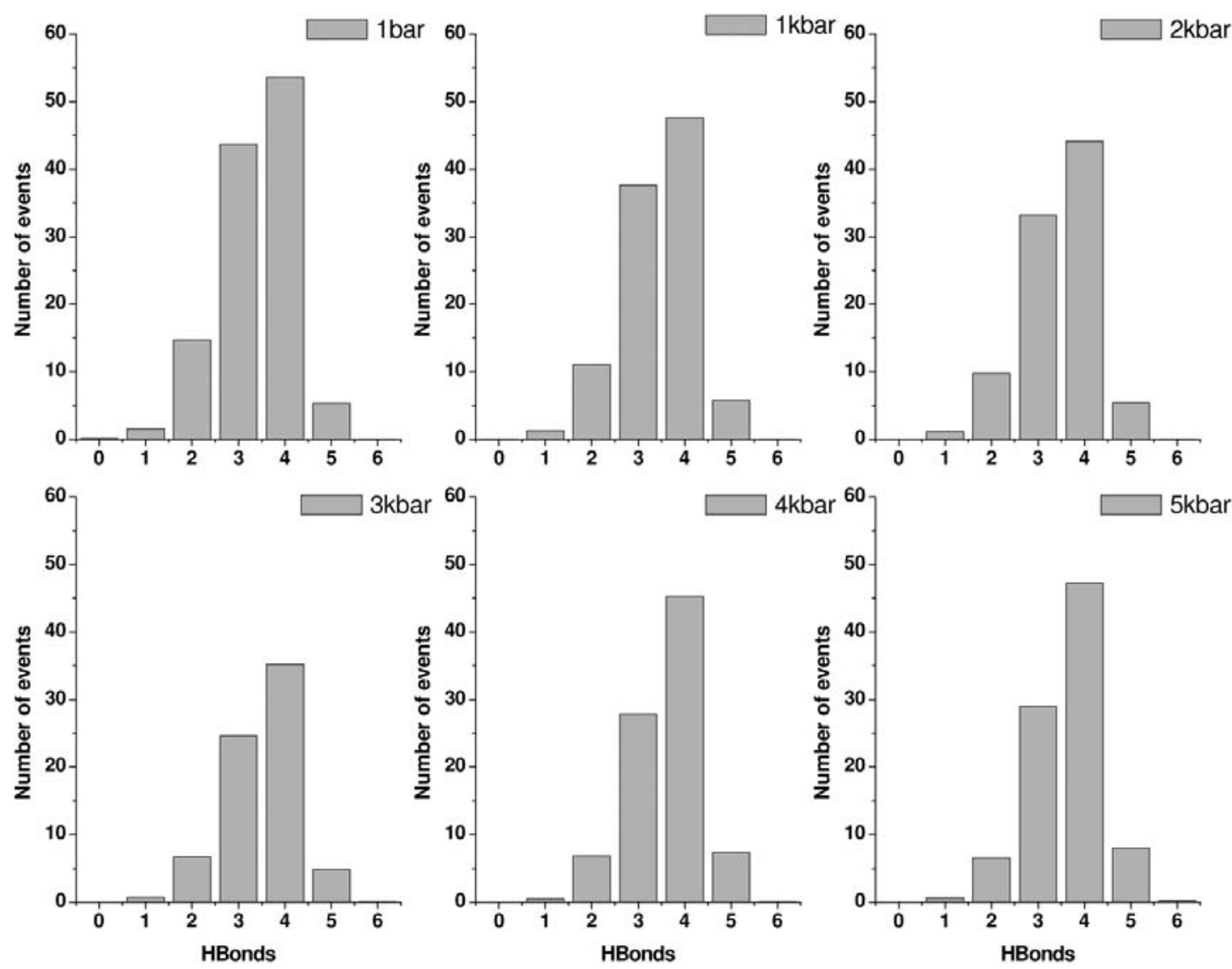

Figure 6. Distribution of hydrogen bonds between water molecules from up to $5 \AA$ of any carbon atom of the solute.

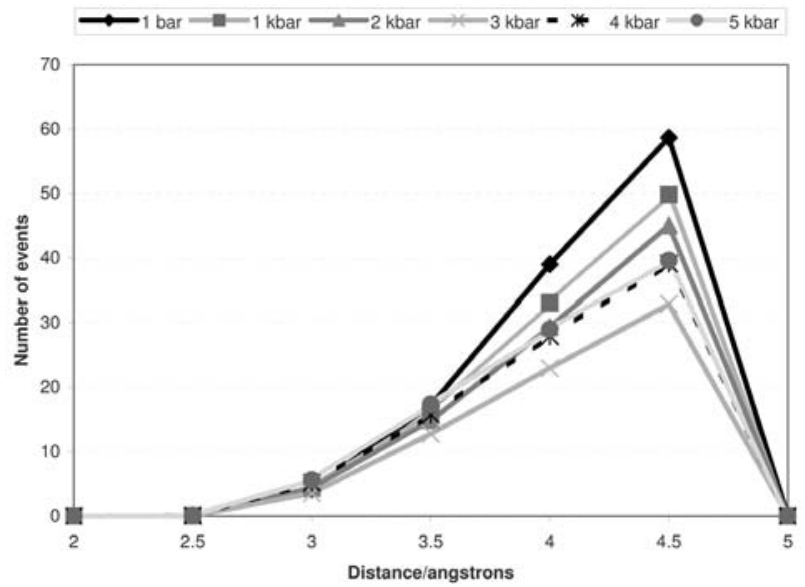

Figure 7. Relative number of water molecules as a function of the distance between two neighboring oxygen atoms at different pressures.

radial distribution functions. Neutron and X-ray diffraction experiments are a good source of structural data of water at high pressures and correlation functions can be built from the study of near neighbor distances between oxygen atoms. ${ }^{14}$

Solute-solute radial distribution function was then calculated between the geometric centers of benzene heavy atoms, and the solute-solvent radial distribution function

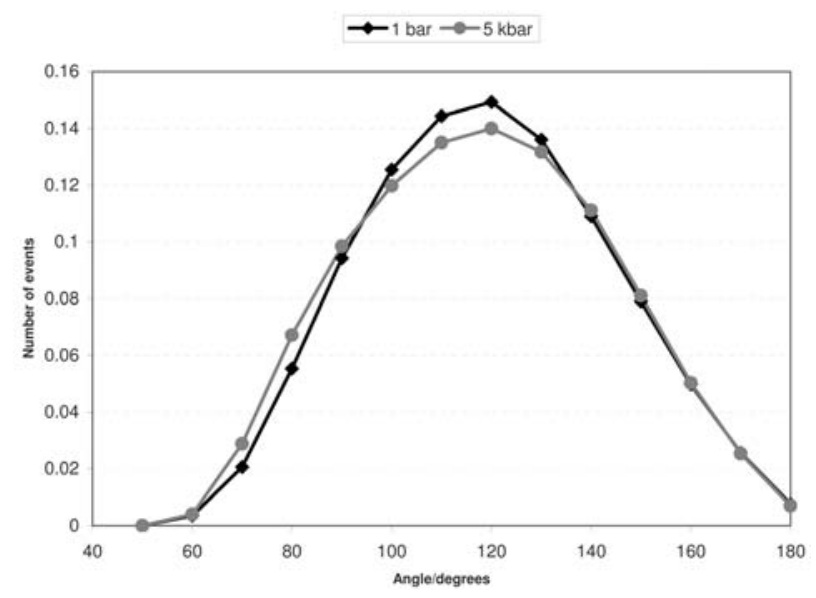

Figure 8. Average of events between three neighboring oxygen atoms as a function of their angle. The values are normalized according to the total number of computed HBonds within $5 \AA$ from any carbon atom of the solute.

was calculated, where the distance between the center of mass of benzene and oxygen atom of water molecules was used in this calculation.

It can be observed (Figure 9a) that in the low-pressure regime ( $\leq 2 \mathrm{kbar}$ ), the probability of finding a benzene molecule near to another one is larger than at high-pressures ( $\geq 3 \mathrm{kbar}$ ). This indicates a desegregation of the benzene 
clusters as the pressure increases. Figure $9 \mathrm{~b}$ shows that the local density of water molecules near a solute also increases due to the more compact molecular packing under further compression.

At pressures higher than $3 \mathrm{kbar}$, a possible explanation for the difference between correlation functions might be due to the increment of the entropy of benzene molecules as an effect of its hydration. The solvation of benzene above $3 \mathrm{kbar}$ was due to the weakening of the water structure, suggesting possible changes of the mean orientation of water molecules ${ }^{37}$ dipoles and extinction of the second solvation layer. From the analysis of the radius of gyration it is possible to observe that there is a restructuring of water molecules.

The location of the maximum of the peaks of the first hydration shell is sharper and slightly left-shifted, indicating a more compact structure. Also, the peak intensities are higher for higher pressures, showing a large number of water molecules in the vicinity of the solute. All these results suggest a more compact distribution of the solvent around the solute. Figures $9 \mathrm{c}$ and $9 \mathrm{~d}$ show a reorganization of water molecules in the first solvation shell with the consequent vanishing of the second hydration shell as the pressure increases.

Some degree of reorganization of the hydrogen bond network towards more angularly bent and weakened bonds can be implicated. This can be readily seen in Figure 10 where the results show normal behavior at 1 bar and a complete loose of the second hydration shell at 5 kbar. As long as the reference of the hydrostatic bath reference pressure gets higher, a more homogeneous distribution of the second hydration shell is produced, as a consequence of a reorganization of water molecules whereas the first hydration shell of water remains the same for all hydrostatic pressures throughout the MD simulations. It can be clearly observed that the former irregular surface at lower pressure suffers gradual smoothing with rising pressure, resulting in a more homogeneous distribution, and consequently undergoes important dependency with orientation.

\section{Conclusion}

The possibility of solvating non-polar molecules (such as benzene) in a very polar solvent (such as water) at high hydrostatic pressures has been shown in this work.

This observation is reasonable and attributable to the unique property of water that becomes less compressible with increasing pressure that drastically modify its liquid structure, but not losing it. We suggest that as pressure increases the entropy of the system does, which depends on angular features of the net and is grounded on the analysis of clustering of benzene molecules at different pressures.

\section{a}

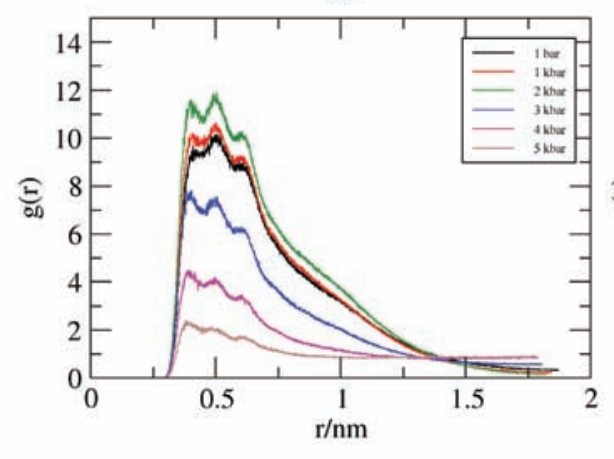

C

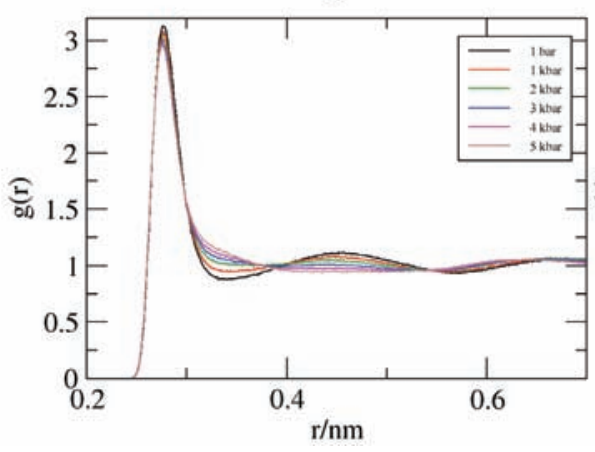

b

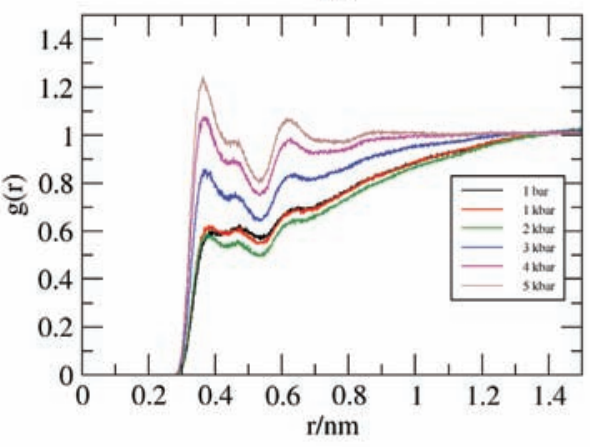

d

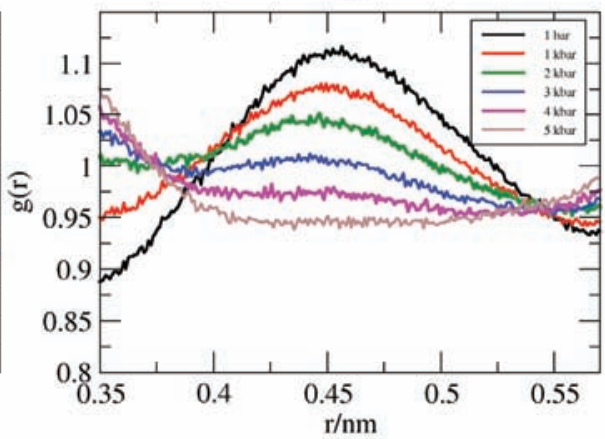

Figure 9. (a) Benzene-benzene radial distribution functions; (b) Benzene-water radial distribution functions; (c) Water-water radial distribution functions; (d) Magnification of (c). 

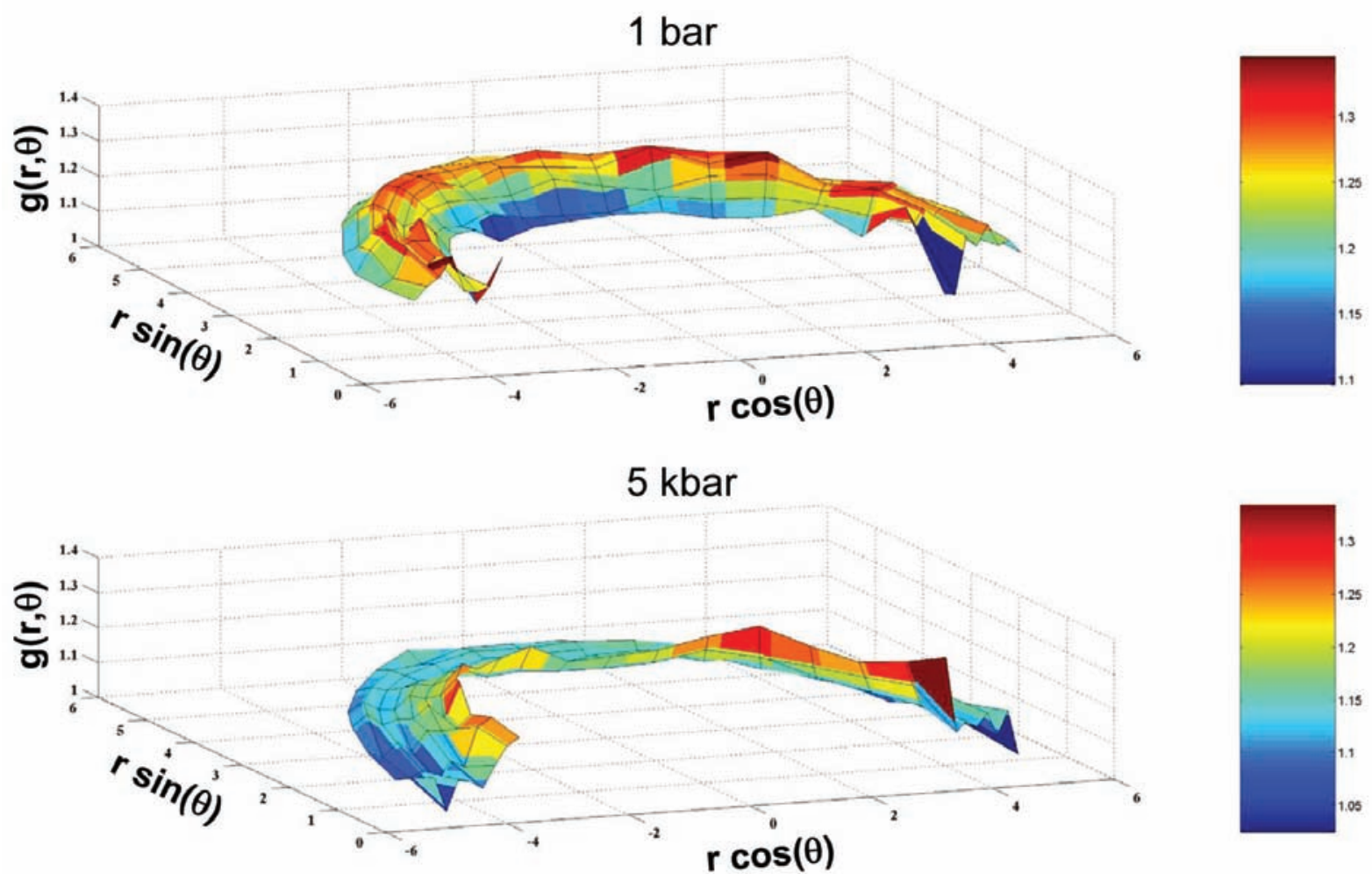

Figure 10. The function $\mathrm{g}(\mathrm{r}, \theta)$ of second solvate layer at (a) 1 bar and (b) $5 \mathrm{kbar}$, respectively.

\section{Acknowledgments}

The Authors wish to thank the Brazilian agencies CNPq, FAPERJ and CAPES for financial support and MSc Samuel Silva Pita to help in manuscript's revision.

\section{References}

1. Shoemaker, B. A.; Wolynes, P. G.; J. Mol. Biol. 1999, 287, 657.

2. Onuchic, J. N.; Nymeyer, H.; García, A. E.; Chahine, J.; Socci, N. D.; Adv. Protein Chem., 2000, 53, 87.

3. Frank, H. S.; Evans, M. W.; J. Chem. Phys. 1945, 13, 507.

4. Kauzmann, W.; Adv Protein Chem. 1959, 14, 1.

5. Hermanm, R. B.; J. Phys. Chem. 1972, 76, 2754.

6. Draghi, C. N.; Àvalos, J. B.; Contreras, O.; Ungerer, P.; Ridard, J.; J. Chem. Phys. 2004, 121, 10566.

7. Eugenia, G. P.; Danielle, B.; Pure Appl. Chem. 2001, 73, 1287.

8. Borges, R. M.; Silva, J. L.; Gay, G. P.; J. Bio. Chem. 1999, 12, 7732.

9. Grigera, J. R.; Caffarena, E. R.; Physica A 2004, 342, 34.

10. Royer, C. A.; Biophys. J. 1995, 68, 1191.

11. Karger, K.; Ludeman, D.; Sceats, B. B.; Phys. Chem. 1995, 99 , 1104.

12. Cavaille, D.; Combes, D.; Ann. N. Y. Acad. Sci. 1996, 799, 212.
13. Bellisent-Funel, M. C.; J. Chem. Phys. 1995, 102, 3727.

14. Ohtaki, H.; Radnai, T.; Yamaguchi, T.; Chem. Soc. Rev. 1997, $26,41$.

15. Lakowicz, J. R.; Weber, G.; Biochemistry 1973, 12, 4161.

16. Sawamura, S.; Kitamura, K.; Taniguchi, Y.; J. Phys. Chem. 1989, 93, 4931.

17. Sawamura, S.; Nagaoka, K.; Machikawa, T.; J. Phys. Chem. B. 2001, 105, 2429.

18. Sawamura, S.; Tsuchiya, M.; Ishigami, T.; Taniguchi, Y.; Suzuki, K.; J. Solution Chem. 1993, 22, 727.

19. Mancera, R. L.; Buckingham, A. D.; J. Phys. Chem. 1995, 99 , 14632.

20. San Román Zimbrón, M. L.; Ortega Blake, I.; J. Chem. Phys. 1997, 107, 3253.

21. Schurhammer, R.; Wipff, G.; New J. Chem. 2002, 26, 229.

22. Hassinen, T.; Peräkylä, M.; J. Comput. Chem. 2001, 22, 1229.

23. Shih, J. H.; Chen, C. L.; Macromolecules 1995, 28, 4509.

24. Schmidt, M. W.; Baldridge, K. K.; Boatz, J. A.; Elbert, S. T.; Gordon, M. S.; Jensen, J. H.; Koseki, S.; Matsunaga, N.; Nguyen, K. A.; Su, S. J.; Windus, T. L.; Dupuis, M.; J. Comput. Chem. 1993, 14, 1347.

25. Brenemann, C. M.; Wiberg, K. B. J.; Comp. Chem. 1990, 11, 361.

26. Rizzo, R. C.; Jorgensen, W. L.; J. Am. Chem. Soc . 1999, 121, 4827. 
27. Damm, W.; Frontera, A.; Tirado-Rives, J.; Jorgensen, W. L.; J. Comp. Chem. 1997, 18, 1955.

28. Berendsen, H. J. C.; van der Spoel, D.; van Drunen, R.; Comp. Phys. Comm. 1995, 91, 43.

29. Lindahl, E.; Hess, B.; van der Spoel, D.; J. Mol. Mod. 2001, 7, 306.

30. Berendsen, H. J. C.; Postma, J. P. M.; van Gunsteren, W. F.; Hermans, J.; B. Pullman 1981, 331.

31. Darden, T.; York, D.; Pedersen, L.; J. Chem. Phys. 1993, 98 , 10089.

32. Essmann, U.; Perera, L.; Berkowitz, M. L.; Darden, T.; Lee, H.; Pedersen, L. G.; J. Chem. Phys. 1995, 103, 8577.
33. Hess, B.; Bekker, H.; Berendsen, H. J. C.; Fraaije, J. G. E. M.; J. Comp. Chem. 1997, 18, 1463.

34. Einstein, A.; Ann. Phys. 1905, 17, 549.

35. Calandrini, V.; Deriu, A.; Onori, G.; Paciaroni, A.; ISIS Facility Annual Report 2001-2002 2002.

36. We thank the referee for this suggestion.

37. Cowan, M. L.; Bruner, B. D.; Huse, N.; Dwyer, J. R.; Chugh, B.; Nibbering, E. T.; Elsaesser, T.; Miller, R. J.; Nature 2005, $434,199$.

Received: June 18, 2008 Web Release Date: May 15, 2009 